\title{
Fracture networks in Rotliegend gas reservoirs of the Dutch offshore: implications for reservoir behaviour
}

\author{
B.D.M. Gauthier ${ }^{1,2}$, R.C.W.M. Franssen ${ }^{1,3}$ \& S. Drei ${ }^{4}$ \\ 1 Nederlandse Aardolie Maatschappij B.V., B.U. Offshore, P.O. Box 23, 1950 AA VELSEN NOORD, \\ the Netherlands \\ 2 corrresponding author; present address:TOTAL Exploration Production - Direction Développe- \\ ment Production, TourTOTAL, 24 Cours Michelet, 92069 PARIS LA DEFENSE, France \\ 3 present address: Shell Deepwater Development Inc. (SDDI), One Shell Plaza, P.O. Box 60833, \\ NEW ORLEANS, LA 70160-0833, USA \\ 4 Institute of Earth Sciences, Vrije Universiteit, De Boelelaan 1085, 1081 HV AMSTERDAM, the \\ Netherlands
}

Manuscript received: 31 October 1996; accepted in revised form:14 December 1999

\begin{abstract}
Fracture systems of Rotliegend gas fields in and at the margins of the northern Broad Fourteens Basin in the Dutch offshore are described in terms of orientation, frequency, origin and type, and in relation to larger-scale structures. First, fracture data collected from core and image logs have been corrected to account for the bias related to the 1-D sampling. Second, these results were integrated with data on fracture cements and diagenesis in order to assess the timing of the fracture network development.

On the basis of their regional extent three phases of fracturing and four orientation trends can be distinguished in the basin:

(1) at Triassic times and related to early diagenesis and burial, NW-SE to NNW-SSE and NE-SW to ESE-WNW particulateshear fractures developed;

(2) during the Mid-Kimmerian and related to the main burial stage, shear-related and dilational-shear-fault-related fracturing occurred parallel with larger-scale faults;

(3) during the Cretaceous and related to uplift, NW-SE and NE-SW joints propagated; a regional joint system developed outside the Jurassic rift basin, preferentially oriented E-WW to ESE-WNW; these joints have not been dated accurately.

The fault-related shear fractures tend to compartmentalise the reservoirs, whereas the regional joints tend to enhance reservoir flow properties. These fracture systems are thought to play a negative or positive role, respectively, but only in fields with poor reservoir quality. Consequently, in such cases small-scale fractures should be taken into account in field development planning.
\end{abstract}

Keywords: Broad Fourteens Basin, gas reservoirs, prediction methods, Rotliegend

\section{Introduction}

Production in the Rotliegend gas fields of the Dutch offshore comes mainly from prolific eolian sandstones of the Slochteren Formation. Fractures are not considered to influence productivity significantly in these porous reservoirs, but fractures contribute to gas production in similar Rotliegend reservoirs in the British sector, for example in the Sole Pit area (Glennie, 1990; Mulder et al., 1992). The present study aims to investigate whether fractures play a significant role in the reservoir behaviour in Rotliegend gas reservoirs of the Dutch offshore. The study area lies partly in the 'Joint Development Area' of the K, L and P Blocks (Fig. 1A).

An improved understanding of the fracture systems may help to explain well behaviour and may assist in evaluation of drilling hazards. Cemented and closed fractures act as barriers to flow, whereas open fractures intersected by the wellbore may increase the flow rates or result in early water breakthrough. Open fracture networks can cause severe mud losses during drilling. Although the present-day in-situ stress regime controls the hydraulic-fracture propagation to 

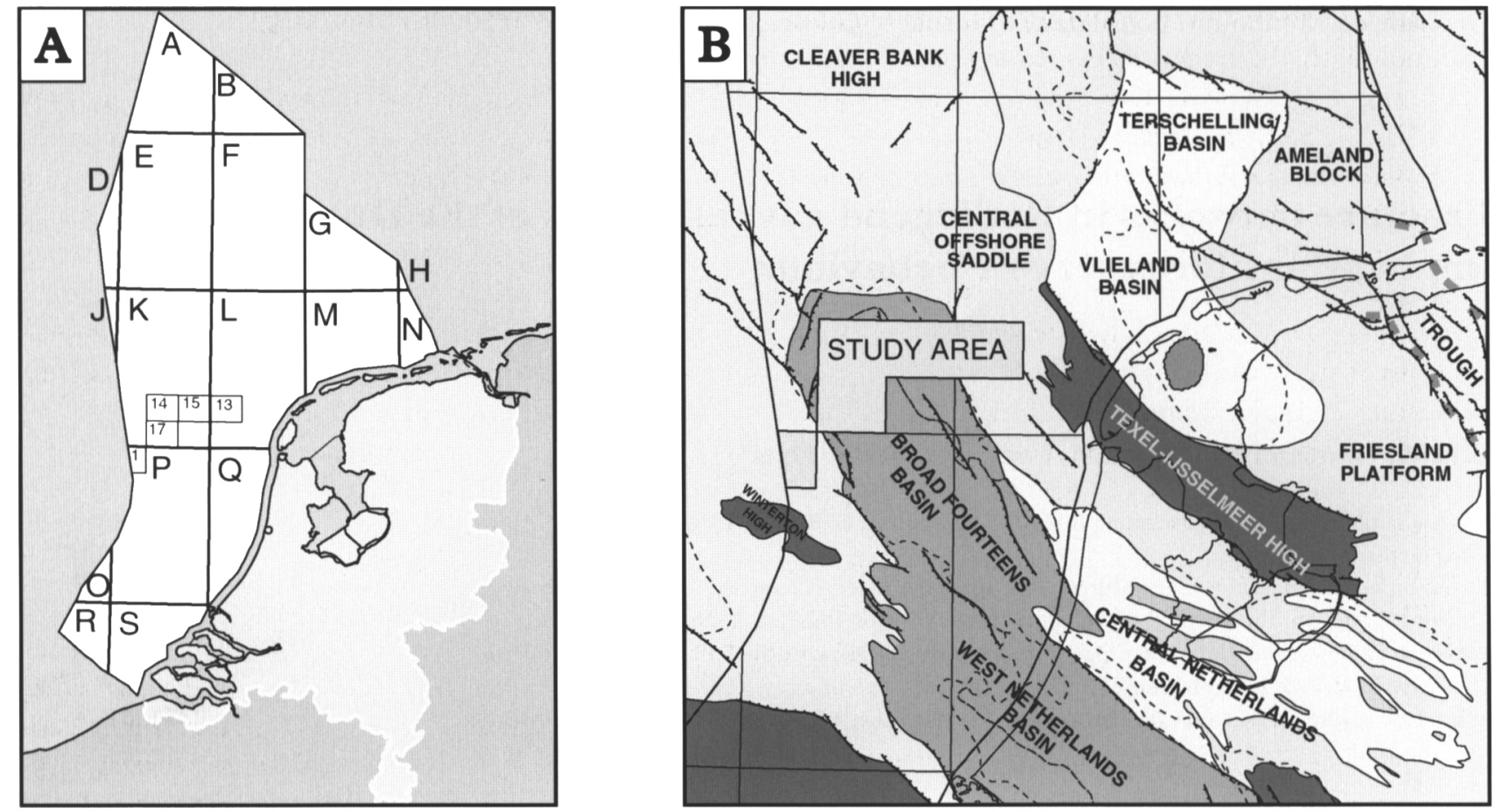

Fig. 1. The study area. The area mapped measures approx. $270 \times 270 \mathrm{~km}$.

A: geographic location.

B: structural setting.

a large extent, the presence of fractures may affect the success of well stimulation as they influence the development of hydraulic fractures. A better understanding of the role of fractures in reservoir performance may influence the further development plans of the mature fields in the study area. A regional study was carried out with the objective to identify (1) the fracture network geometry, (2) the tectonic significance of the fractures, and (3) the impact of fractures on reservoir behaviour.

Since fractures are small-scale structures, they are below the resolution of seismic data as well as most conventional well logs; consequently they can only be sampled by cores and image logs. These data sources typically yield sparse, incomplete and biased data sets. A systematic methodology needs therefore to be applied to all available core and well data in order to integrate and compare the data sets.

In the present contribution, fracture geometry and structural interpretation of the fracture networks are considered to be important aspects. Geometrical fracture analysis comprises geometrical corrections used to reduce the errors induced by the orientation of the well trajectory and by statistical and probabilistic methods. Structural geological interpretation of fractures aims at: (1) interpreting fracture development within the framework of the structural geological evolution of the study area framework, and (2) assessing their relation with larger-scale structures. From this, fracture-network models can be derived which contain the most significant fracture parameters that may affect reservoir behaviour.

\section{Geological setting}

The study area is located in, and at, the margins of the northern Broad Fourteens Basin (Fig. 1B). The basin intersects to the north the Central Offshore Saddle, which is the southerly continuation of the Dutch Central Graben and is bounded to the west by the Indefatigable Shelf and to the east by the Texel IJsselmeer High.

The Early Permian Upper Rotliegend Group is a continental succession consisting of claystones, siltstones, sandstones and conglomerates. The group is subdivided in formations and members that comprise distinctive facies associations, interpreted as the products of deposition in fluvial, eolian, sabkha and lacustrine environments. The base of the Rotliegend is marked by an unconformity with the underlying Carboniferous coal-bearing succession (source rock). The overlying Zechstein carbonates and evaporites form the reservoir seal. An extensive review of the sedimentary context can be found in Van Adrichem Boogaert \& Kouwe (1993).

The northern Broad Fourteens Basin is a Jurassic basin formed by step faulting along the margin of the Texel-IJsselmeer High. The basin was inverted during 
the Late Cretaceous (Van Wijhe, 1987). The tectonic evolution of the basin and its surroundings can be divided into the following four main phases (Ziegler, 1982; Van Wijhe, 1987; Wride, 1995):

1 Triassic-Middle Jurassic: this interval was marked by differential subsidence of some major graben systems, which initiated crustal extension and rifting during which the entire area was subjected to extension. This extension reactivated Late Hercynian fracture systems. At the Rotliegend level, this resulted in block faulting and rotation, predominantly along NW-SE trending faults. The Zechstein salt deposits decoupled the deformation from the 'basement'. Extension in the overlying strata was accommodated by movement along NW-SE trending faults. At the transition from the Oxfordian to the Kimmeridgian, the basin became subjected to erosion as a consequence of wrenching in compensation for continued crustal extension in the Central North Sea Graben (Van Wijhe, 1987).

2 Late Jurassic-Early Cretaceous: thermal doming related to an increase in the rate of crustal extension across the rift system: the 'Mid-Kimmerian event' (Ziegler, 1982). This tectonic activity was accommodated by dextral movements along NWSE trending faults and was accompanied by tilting and erosion. Subsequent thermal subsidence, the 'Late Kimmerian event', controlled the deposition of the Late Jurassic Delfland Group. This subsidence is interpreted to represent the transition from the rifting to the sag phase. The early Late Cretaceous was a period of tectonic quiescence.

3 Late Cretaceous-Early Tertiary: the area was subjected to sinistral transpression movements along previous tensional faults, which caused the inversion of the basin and resulted in uplift, folding, reverse faulting and erosion. Associated shortening within the basin was accommodated by reverse reactivation along existing faults, by the formation of pop-ups, and by open folding.

4 Late Tertiary: regional downwarping related to the post-rifting subsidence which caused extension, locally modified by salt diapirism. Reverse faults were reactivated as normal faults, locally with some strike-slip components, and resulted in a renewed uplift of the basin.

The complex structural geology of this area is explained by the presence of pre-Saalian 'basement' fault trends, which controlled the main tectonic events. These faults were repeatedly reactivated by oblique-slip movements responding to an E-W to ESE-WNW regional extension that encompassed the entire North Sea area (Bartholomew et al., 1993; Wride, 1995).

\section{Fracture sampling methodology}

Fractures were studied using two different sources of data. The prime source consists of core material on which fractures can be inspected and from which they can be described. Cores have, however, a limited length. The second source consists of borehole imaging logs (BIL) from which only fracture images for orientation analysis are available. These logs are generally of extensive length. The way image logs were treated as virtual cores has been presented by Homann \& Gauthier (1995) and by Frikken (1996).

\section{Genetic fracture parameters}

The fracture description and data collection from the cores focused on fracture orientation, mechanical fracture origin, fracture type with respect to the effect on fluid flow, and (relative) timing of fracture development. Thin sections were made at selected locations in order to investigate the macroscopic core observations further and to assess the diagenetic cement paragenesis in host rock and fracture. First, we will discuss the data collection.

\section{Fracture origin}

The mechanical origin of fractures (Hancock, 1985; Price \& Cosgrove, 1990) indicates the stress regime under which the fractures formed (Engelder \& Geiser, 1980; Bergerat et al., 1992) and is a key parameter to understand their impact on reservoir behaviour (Loosveld \& Franssen, 1992; Fulljames et al., 1996). The following four mechanical origins are commonly distinguished (Price \& Cosgrove, 1990).

1 Tension fractures or joints form perpendicular to $\sigma_{3}$ (smallest principal stress) and are characterised by movement perpendicular to the fracture plane. If not cemented, joints improve reservoir permeability and connectivity.

2 Shear fractures form as conjugate sets of Coulomb slip planes oblique to $\sigma_{1}$ (largest principal stress). The intersection of the fracture planes is parallel to $\sigma_{2}$ (intermediate principal stress). They are characterised by movement in the fracture plane. Generally, shear fractures result in permeability reduction. One should distinguish, however (Loosveld \& Franssen, 1992), between particulate-shear fractures (i.e., the sliding and rolling of intact grains past each other, occurring under shallow-depth conditions by fracture dilatation) and cataclastic shear fractures (i.e., grain crushing occurring under high pressure and temperature by fracture compaction or dilatation). Particulate-flow shear fractures can lead to permeability increase and 
Table 1. Recognition criteria for defining mechanical origin of fractures from core data (after Kulander et al., 1990).

\begin{tabular}{|c|c|c|c|}
\hline joints & dilational shears & shear fractures & core-induced \\
\hline $\begin{array}{l}\text { perpendicular to bedding } \\
\text { open } \\
\text { irregular fracture plane } \\
\text { plumose features }\end{array}$ & $\begin{array}{l}\text { combination of joints } \\
\text { and shear fractures } \\
\text { characteristics }\end{array}$ & $\begin{array}{l}\text { shear offset } \\
\text { slickensides } \\
\text { anastemosing bands } \\
\text { conjugate sets }\end{array}$ & $\begin{array}{l}\text { long } \\
\text { along core edge } \\
\text { helicoidal plane } \\
\text { petal features }\end{array}$ \\
\hline
\end{tabular}

cataclastic shear fractures generally result in permeability reduction.

3 Dilational shear fractures have movement components in, and perpendicular to, the fracture planes. If uncemented, dilational shears improve reservoir permeability and connectivity.

4 Coring-induced fractures form in response to stress changes induced by the drilling and coring process (Kulander et al., 1990). They are rejected from the analysis because they do not occur in the subsurface.

Diagnostic criteria to recognise the mechanical origin of fractures are summarised in Table 1. Kulander et al. (1990) and Price \& Cosgrove (1990) provide an extensive discussion on this topic.

\section{Effect on fluid flow}

Three types of fracture planes are distinguished with respect to their effect on fluid flow: open, closed and cemented.

\section{Timing}

(Relative) timing should be considered in order to assess the development of the fracture network and to relate fracture formation to the structural evolution of the area. The relative timing of fracture development can be established from abutting relationships (Engelder, 1985; Price \& Cosgrove, 1990). Joints tend to abut against any pre-existing plane of weakness (i.e., bedding, older fractures). The joints can therefore be assumed to be younger if a joint set systematically abuts against another set. In contrast, shear fractures tend to offset older fracture planes. Consequently, a shear-fracture set that systematically cross-cuts another set can therefore be assumed to be the younger set. In order to apply these abutting relationships, a clear determination of the fracture origin (joints versus shear fractures) and a statistical approach based on a large number of observations are required. A more accurate timing method is to relate the fracture cement paragenesis and the isotopic signatures of the cements to the burial history of the wells under study (Franssen et al., 1993). The method consists of determining the cement types occurring in the host rock and in the fractures. Stable-isotope data combined with fluid-inclusion analyses of the matrix and fracture cements are used to determine the pore-water origin and paleotemperatures during which the cements precipitated. If this can be done, it is possible to link the diagenetic history and the timing of the fracture events with the burial curve and consequently with the structural evolution of the basin. This method has the advantage of giving results in line with the large-scale geological history, but it is tedious and time-consuming and has been applied on a limited scale only.

\section{Geometrical parameters}

The following three geometrical parameters are at least required for quantifying a fracture network: orientation, size and spacing (or frequency, which is $1 /$ spacing).

\section{Orientation}

In the case of non-oriented cores, the following method for determining the orientation of subsurface planes was applied (Fig. 2). The fracture orientation was measured relative to the orientation of a known feature. In a sabkha environment, shale layers can be assumed to represent a horizontal paleoplane at the time of sedimentation. Therefore, these layers are currently conformable to the structural dip. With a 3-D goniometer, the orientations of the shale layers and the fracture planes are measured relative to a fixed reference system with the $\mathrm{Y}$-axis parallel to the core axis (Fig. 2A). This reference system is then rotated within the general geographic system so that the core axis becomes situated parallel to the well trajectory (Fig. 2B). A step-by-step rotation is then applied around the core axis until the shale beds match the known (i.e., from seismic or dipmeter data) regional structural dip at best (Fig. 2C). The same rotations are concurrently applied to the fractures, and the final co-ordinates define their true subsurface orientation. This method allows sampling of large parts of the core at relatively low costs and is easily implemented. The method was validated independently by paleomagnetic core-orientation techniques. The accuracy is in the range of $10^{\circ}$. Note that, in the case of vertical 


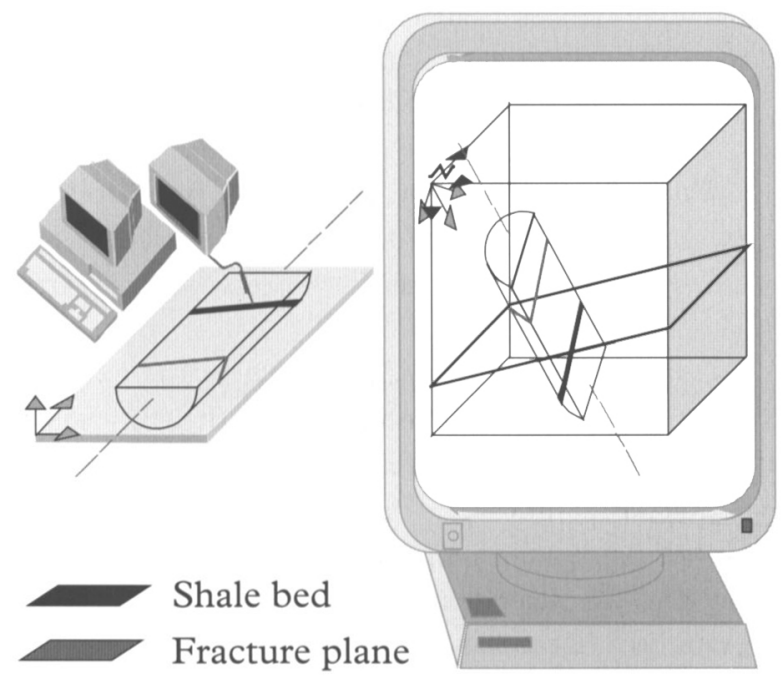

C

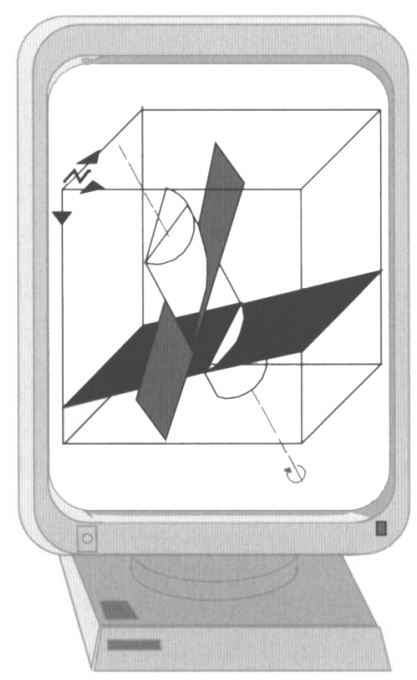

Fig. 2. Orientation of core-data procedure. See also the text under the heading 'Geometrical parameters'.

A: digitisation.

B: well trajectory match.

C: structural dip match. wells drilled in areas with small structural dips, the method cannot be used (a maximum angle of $75^{\circ}$ between core axis and structural dip direction was deemed necessary).

Once the subsurface fracture orientations are known, cluster-analysis techniques (Diday, 1971) and statistics of orientation data (Watson, 1966; Mardia, 1972) are used to define the number and the preferred orientations of the fracture sets. Then, the correction method proposed by Terzaghi (1964) to evaluate the sampling error related to the orientation of the well trajectory with respect to the fracture set orientation is applied. This method consists of weighting each directional data as a function of the cosinus of the angle between the core axis and the fracture pole vector (Fig. 3A). This simple correction is unrealistic, however, since it assumes that fractures are regularly spaced and of infinite size. Kulatilake (1988) and $\mathrm{Ku}$ latilake et al. (1990) proposed a 3-D correction based on probabilistic functions. This correction methodology is considered to require too many assumptions, however, in the case of limited core data and was judged beyond the scope of the present study. Therefore, Terzaghi's (1964) correction method was employed as a weighting function to evaluate the degree of underestimation (or overestimation) of each orientation family per well. This weighting function approximates the number of fractures that a well drilled perpendicularly to the fracture set would have intersected. Although the absolute number of fractures resulting from this correction may appear unrealistic, this method gives an unbiased relative frequency of each fracture set (Fig. 3B).
A

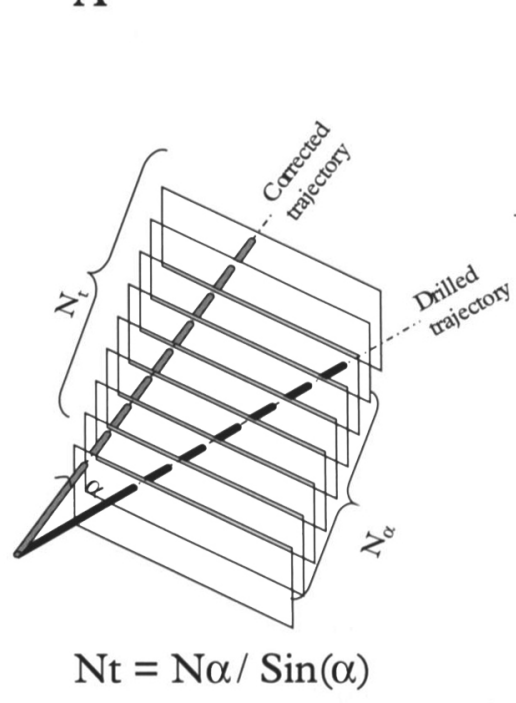

B
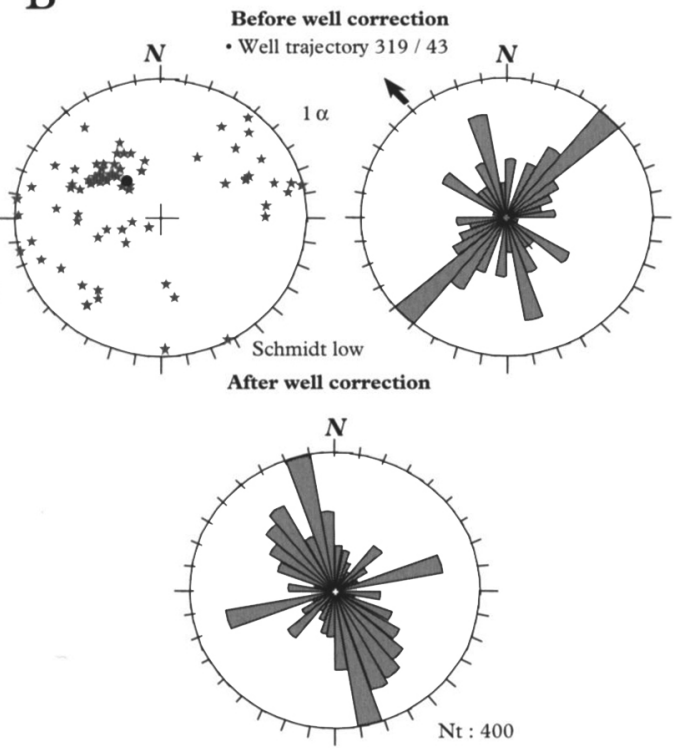

Fig. 3. Effect of well-orientation correction on fracture-orientation density. A: the apparent number of observed fractures is corrected in relation to the cosinus of the angle between the mean fracture pole and the axis of the well. $B$ : in this real example, the total number of fractures has been multiplied by 5 . The NNW-SSE family appears as the dominant fracture set. Due to the orientation of the well trajectory, the NE-SW family was overestimated and the ENEWSW family was underestimated in sampling. $\mathrm{N}_{\alpha}$ is the observed fracture number; $N_{t}$ is the corrected fracture number. 
Size

Deterministic determination of the average size of fractures intersected by a simple core is practically impossible. The probability of a core to intersect a fracture, and the chance of this intersected fracture to terminate in the core depend, however, on the fracture size and on the borehole size (Fig. 4). A geometric probability model allows estimation of the fracture size. The model relates the extent of the fracture to the probability of this fracture to intersect the core versus the probability of the same fracture to terminate within the core. Again, this approach is not expected to give accurate absolute estimates of fracture size since it: (1) assumes square or circular-shaped fractures, and (2) is sensitive to poor sampling. It allows, however, the relative size of each fracture set to be assessed objectively.

\section{Spacing}

Fracture spacing describes the distance between the fracture planes measured along a scanline oriented parallel to the average fracture pole. Due to limited sampling, true fracture spacing can seldom be measured in well data. For joints, bed thickness is often considered as the main controlling parameter on their spacing (Ladeira \& Price, 1981). Joint spacing tends to increase with bed thickness (Ladeira \& Price, 1981; Narr \& Suppe, 1991) up to a certain limit after which it remains constant (Wu \& Pollard, 1995). In addition, other parameters such as lithology, grain size, porosity, and structural position (amount of deformation) also influence spacing. Narr \& Lerche (1984) proposed various probabilistic methods to determine joint spacing in layered rocks from core data. Based on field data, several spacing distribution types have been described: log-normal (Narr \& Suppe, 1991), exponential (Priest \& Hudson, 1976) and normal (Huang \& Angelier, 1989). The evolution of joint spacing with increasing deformation, from an initial negative exponential distribution through log-normal to a normal spacing distribution, has been described from analogue experiments on brittle coatings (Rives et al., 1992). In reservoir-characterisation studies, however, estimation of the aggregate fracture frequency (i.e., the inverse of spacing) of the complete fracture network (comprising various sets) is required.

In the case of the Rotliegend reservoirs, the massive sandstones are not considered as layered rock masses although the interbedded shale layers may act as layers of mechanical contrast. In order to substantiate this, the relation between bed thickness and fracture spacing was investigated in a couple of cases using image-analysis techniques. In core photographs, shales and sandstones have different colours and textures. Using scanned images of core photographs, individual layers of sandstone and shale can be identified by their relative change in grey colour intensity. The corresponding bed thickness can be calculated from this. Figure 5 shows the relation between fracture frequency and bed frequency as a function of depth. It is clear rom this example that some correlation between fracture and bed frequencies occurs only at the top of the core. Towards the base of the cored interval, the presence of a fault zone has an overriding impact and fully controls fracture frequency. In this sandstone environment, it is therefore concluded that bed thickness has a negligible impact upon fracture density.

In general, determining the spacing distribution for each fracture set from core drilled in 'random' orientations with respect to the fracture orientation is a very difficult issue due to the limited amount of data. If one wants to compare frequency distributions between areas (per well, for instance), or to assess the influence of fracture set, type or distance to the nearest

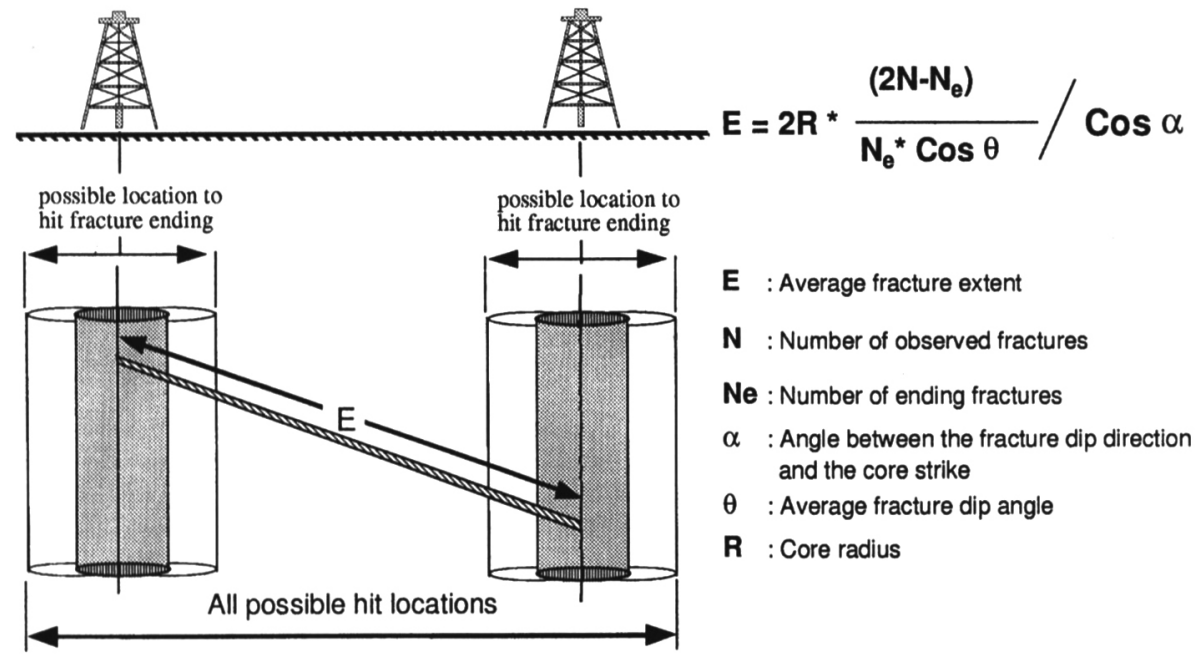

Fig. 4. Two-dimensional geometric probabilistic model of average fracture extent. See also the text under the heading 'Geometrical parameters'. 


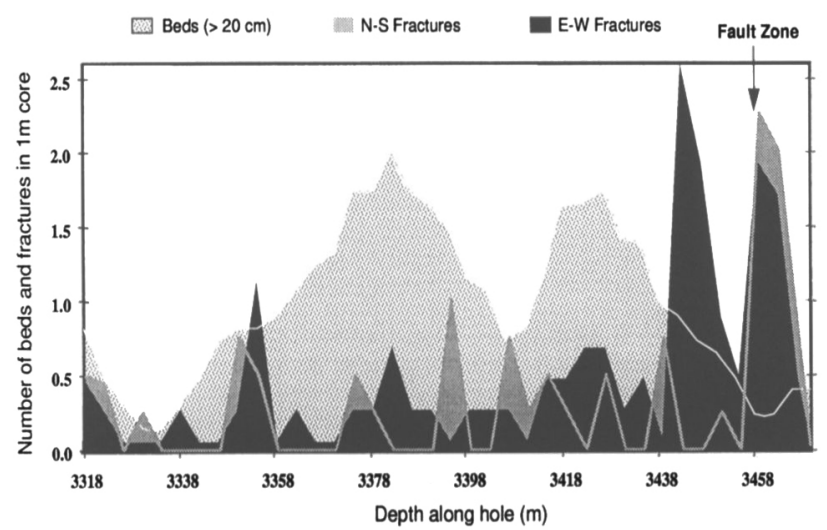

Fig. 5. Relation between beds thicker than $20 \mathrm{~cm}$ and fracture intensity in a typical studied Rotliegend core with two fracture sets. Note that there is no clear correlation between bed thickness (inversely proportional to bed frequency) and fracture frequency.

fault upon fracture frequency, the data sets have to be differentiated further and only very small data sets are thus available, so that deterministic methods are not applicable. Fracture frequency was therefore assessed as an estimate of the probability of intersecting a fracture of any kind per unit length of wellbore. This approach implies the following assumptions: (1) there is no distinction of orientation families; (2) cores are arbitrarily oriented with regard to fracture orientation (this is justified by the fact that no wells have been drilled with the main objective to maximise or minimise the number of intersected fractures); (3) fracture spacing versus bed thickness relations are not the main control on fracture spacing (see above); (4) the available data for each field yield representative samples (this may require combining data of several wells).

Given these assumptions, each data set (i.e., well) is considered as a random sample through the true spacing distribution law. In other words, we consider each well as an independent random variable of a random (i.e. Poisson) spacing distribution. The probabil- ity density function (PDF) of spacing obtained from the measurements can then be compared with various theoretical PDFs, commonly negative exponential distributions with average spacing, $\mu$ (Priest \& Hudson, 1976; Fig. 6). The probability of obtaining a spacing smaller than a given value, $s$, can be expressed as the number of spacings smaller than $\mathrm{s}$ with respect to the total number of spacings observed. For the example illustrated in Figure 6, the well is characterised by an average fracture spacing of $30 \mathrm{~cm}$ and the chance of having at least one fracture per metre of core is in this case $80 \%$.

This method estimates average values of fracture spacing, assuming a Poisson distribution of evenly distributed spacings along the sampling line (core). Fracture clustering cannot be addressed specifically. Clustering leads to flattening of the observed PDF curves, however, which then resemble more a lognormal distribution. This observation can be applied to identify the presence of fracture clustering.

\section{Combining data}

Since the wells are independent random variables, the method presented here allows the data of various wells to be combined. It is then possible to combine data according to any chosen criterion (such as field, location, distance to nearest fault, etc.). A more representative picture of the study area can be obtained, and fracture occurrence can be predicted in general terms. A limitation of the method is that the contribution of a particular fracture set or of a particular fracture type cannot be established because the method does not allow splitting of the data sets.

\section{Fracture description}

Thirty-three wells distributed over fifteen fields and four exploration prospects have been studied. More

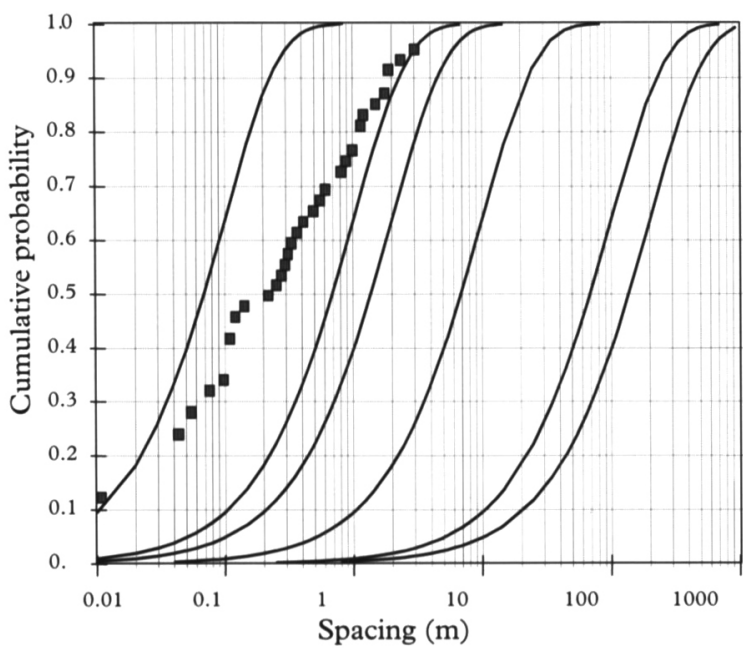

Measured P.D.F.

$P(s)=\sum_{i=0}^{i=s} N_{i<s} / N t$

Well data

Theoretical P.D.F

$$
P(s)=\int_{0}^{s} \lambda e^{-\lambda v} d s
$$

Mean Fracture Frequency: $\lambda=1 / \mu$

$$
\mu(\mathrm{m})
$$

$-0.1 ; 1.0 ; 2.0 ; 10.0 ; 100.0 ; 200.0$ (from left to right)
Fig. 6. Theoretical probability density function (PDF) for fracture spacing with negative exponential distribution. See also the text under the heading 'Geometrical parameters'.

$\mathrm{Nt}=$ total fracture number. $\mathrm{Ni}_{\mathrm{i}<i}=$ number of fractures with spacing smaller than $s ; \mu=$ average spacing values for reference. 
than 1700 fractures have been measured and analysed using core and BIL data. The detailed results of each well and field are beyond the scope of the present contribution, so that we will limit ourselves to general descriptions and conclusions.

\section{Fracture geometry}

An overview of the fracture trends that have been identified in the Broad Fourteens Basin and its margins is shown in Figure 7 and Table 2. The fracture networks are relatively complex and vary as functions of the structural location. Four main fracture trends prevail: NW-SE, NE-SW, N-S and E-W.The fractures form vertical to subvertical sets or conjugate systems. Within each well, the dominant fracture trend often matches the orientation of the nearest seismically imaged fault trend. The NW-SE, NE-SW and N-S fracture trends correspond to fault trends present in the study area. In the northern margin, large-scale E-W faults are observed.

Figure 8 shows the average fracture-size estimates using the method described above. The fractures with a N-S, NW-SE and E-W trends are relatively short, irrespective of their geographic location or origin; those with a NE-SW trend show a larger spread in size related to the fracture origin. In wells where shear fractures are present, the NE-SW trending fractures tend to be relatively long, whereas the NE-SW trending fractures tend to be relatively short in wells where joints have been observed.

Figure 9 shows the average spacing distributions as functions of the structural location of the wells. Aver-
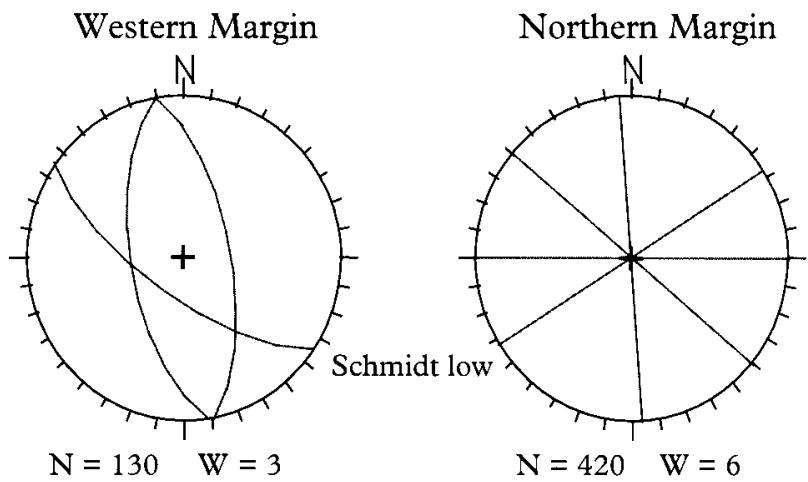

Broad Fourteen Basin

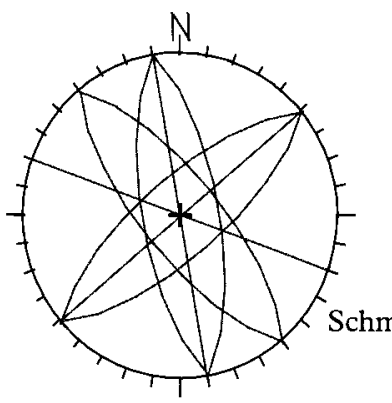

Eastern Margin

$$
\mathrm{N}=800 \quad \mathrm{~W}=14
$$

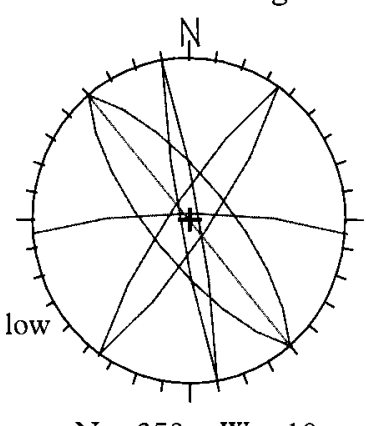

$\mathrm{N}=350 \quad \mathrm{~W}=10$

Fig. 7. Preferred Rotliegend fracture orientations in the study area as a function of the structural location.

$\mathrm{N}=$ number of data. $\mathrm{W}=$ number of wells.

age spacing values range from $0.3 \mathrm{~m}$ (western margin) to $1.0 \mathrm{~m}$ (eastern margin). In addition, all observed PDFs of spacing show a flattening compared to the theoretical functions, with the exception of the data from the northern margin. This flattening has been correlated to the occurrence of fracture clustering. This clustering can be either due to the presence of a

Table 2. Fracture style summary of Rotliegendes in the study area. Note that this represents the dominant trends only.

\begin{tabular}{|c|c|c|c|c|c|}
\hline \multirow[t]{2}{*}{ structural location } & \multicolumn{2}{|c|}{ average fracture orientation } & \multirow{2}{*}{$\begin{array}{l}\text { origin } \\
\text { dip }\end{array}$} & \multirow{2}{*}{$\begin{array}{l}\text { type } \\
\text { open or cemented with }\end{array}$} & \multirow{2}{*}{$\begin{array}{l}\text { relation } \\
\text { with faulting }\end{array}$} \\
\hline & orientation & strike orientation & & & \\
\hline \multirow[t]{2}{*}{ western margin } & $\mathrm{N}-\mathrm{S}$ & conjugate & cataclastic shear & quartz & yes \\
\hline & NW-SE & subvertical & joint & anhydrite & no \\
\hline \multirow[t]{4}{*}{ northern margin } & $\mathrm{N}-\mathrm{S}$ & vertical & joint & undifferentiated & yes \\
\hline & NW-SE & vertical & joint & undifferentiated & yes \\
\hline & NE-SW & vertical & joint & open or undifferentiated & yes \\
\hline & $\mathrm{E}-\mathrm{W}$ & vertical & joint & open or undifferentiated & yes \\
\hline \multirow[t]{6}{*}{ Broad Fourteens Basin } & $\mathrm{N}-\mathrm{S}$ & conjugate & shear & quartz, siderite, Fe-dol. & yes \\
\hline & & vertical & joint & open or undifferentiated & yes \\
\hline & NW-SE & conjugate & particulate-flow shear & dolomite & yes \\
\hline & & vertical & dilational shear \& joint & open or anhydrite & no \\
\hline & NE-SW & conjugate & particulate-flow shear & dolomite & yes \\
\hline & & vertica & dilational shear \& joint & quartz, siderite & yes \\
\hline \multirow[t]{5}{*}{ eastern margin } & N-S & conjugate & cataclastic shear & undifferentiated & yes \\
\hline & NW-SE & conjugate & cataclastic shear & Fe-dolomite, quartz & yes \\
\hline & & verticald & dilational shear \& joint & open or anhydrite & no \\
\hline & NE-SW & conjugate & cataclastic shear & clay or undifferentiated & yes \\
\hline & EWw & subvertical & joint & open & no \\
\hline
\end{tabular}




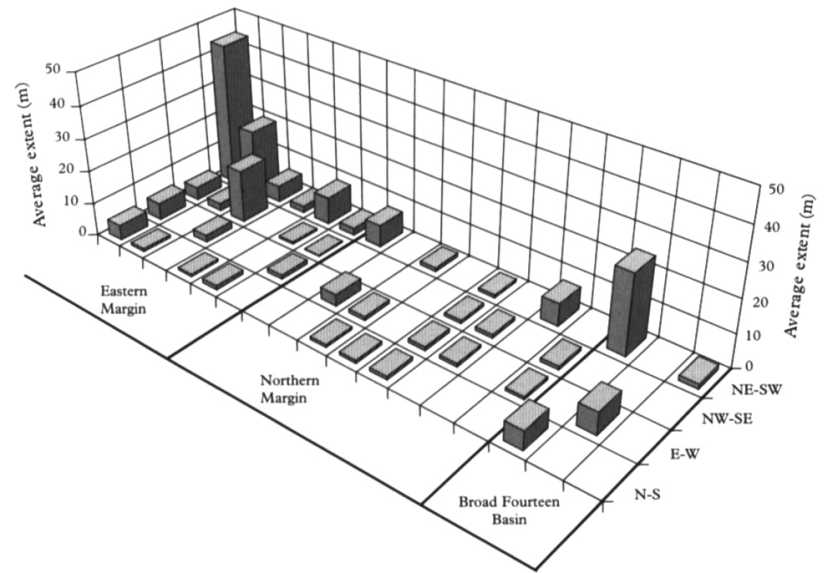

Fig. 8. Average fracture extent of preferential Rotliegend fracture trends in the study area.

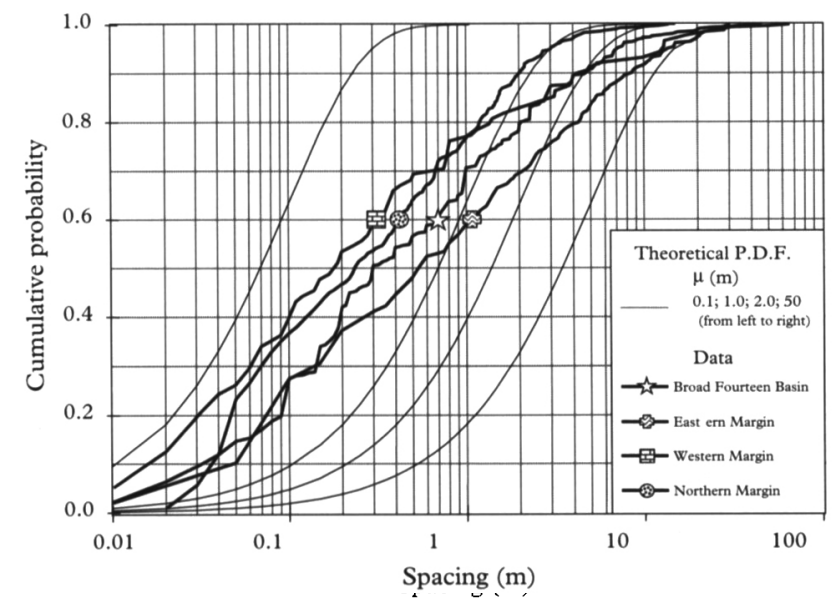

Fig. 9. Cumulative fracture spacing distributions of all studied data as a function of structural location.

fault, or result from a lithology contrast. In order to verify whether fracture clustering and fracture spacing can be related to the proximity of seismically visible faults, the well data have been combined as a function of distance to the nearest fault. No clear relationship showing that fracture spacing increases towards the fault could be established. Possible reasons for this unexpected result are: (1) the wells are outside the damage zone around the seismically visible fault and therefore this fault does not affect the fracture frequency; (2) the presence of subseismic faults remains undetected, resulting in an incorrect ranking of the well data.

We investigated whether the orientation of the nearest fault influences the average fracture spacing (Fig. 10). Indeed, some fault trends appear to have more influence on fracture spacing than other trends do. E-W striking faults - and to a lesser extent NW$\mathrm{SE}$ and N-S faults - tend to induce higher fracture frequencies than NE-SW faults.
Fracture style and timing

Table 2 also indicates the mechanical origin and type of the fracture for each orientation set. Whenever possible, the fracture cement fill has been determined and related to the overall diagenetic history of the study area.

In the Broad Fourteens Basin, early dolomite cement is related to the occurrence of particulate-flow shear fractures. Both indicate deformation during shallow burial $(500-1000 \mathrm{~m})$. With increasing burial, ferro-dolomite and quartz cements precipitated in association with cataclastic shear fractures. Associated with the deepest burial are siderite, quartz and anhydrite cements. This was followed by basin uplift and the development of joint systems.

A similar diagenetic cement paragenesis, but with an additional phase of illite formation during uplift, has been established for the eastern margin. No particulate-flow shear fractures have been observed there. The cataclastic shear fractures developed during deeper burial and the NW-SE trending joints developed during uplift. Open E-W joints seem to represent the last phase of deformation but cannot be dated accurately.

In the western and northern margins, no detailed diagenetic cement study has been undertaken. A similar cement paragenesis has, however, been observed and a similar chronology is assumed. Although the number of abutting relationships observed was relatively small, the relative timing of the various fracture events derived from these data agrees with the chronology of the fractures based on the integrated diagenetic studies.

\section{Structural interpretation}

The geometrical and genetic characterisation of the fracture systems allows a structural geological inter-

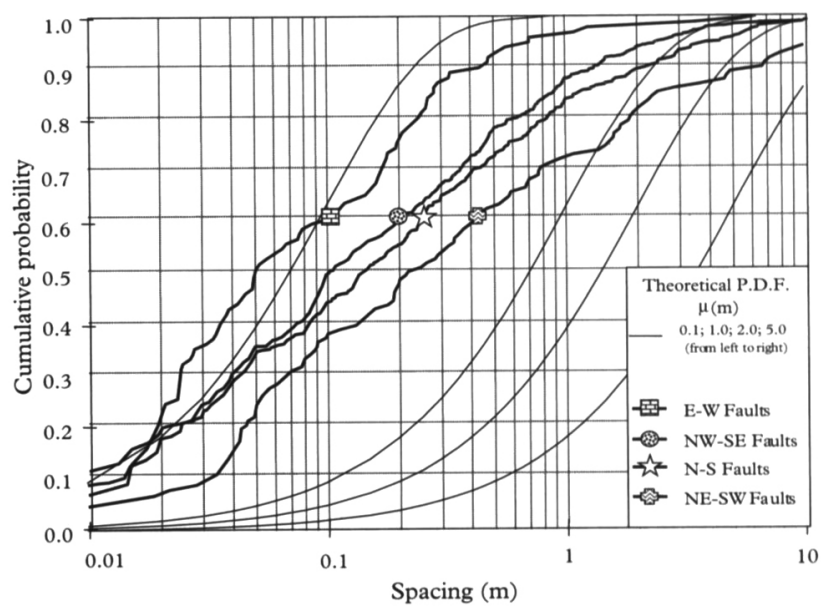

Fig. 10. Cumulative fracture spacing distributions of all studied data as a function of the orientation of the nearest fault. 
pretation of these systems within the framework of the structural evolution of the study area. In the Broad Fourteens Basin, three phases of fracturing can be identified (Fig. 11A). Particulate-flow shear fractures formed under triaxial deformation (Reches, 1983) ) at an early stage of the diagenesis, during Triassic times. Cataclastic shear fractures and dilational shears and joints developed during the main burial phase when $\sigma_{1}$ and $\sigma_{2}$ swapped orientations and when all the main fault trends were re-activated. Obliqueslip slickensides and small reverse offsets are observed locally. This is the most complicated tectonic phase and is interpreted to result from a combination of oblique-slip reactivation of basement trends and increasing burial. During the Late Cretaceous uplift phase of the basin, the principal stresses swapped orientations again and dilational shear fractures and joints developed parallel to the existing fault trends.

On the western and eastern margins of the basin, fracturing apparently started later, during the deepest burial (Fig. 11B). NW-SE and NE-SW trending cataclastic shear fractures developed simultaneously and represent oblique extension during the main phase of burial. Slight clockwise rotation of the stress field at the end of the burial and or the beginning of the uplift resulted in the formation of steeply dipping N-S trending cataclastic shear and dilational shear fractures. The orientation of these fractures is generally controlled by the nearest fault. During the uplift phase, the principal stresses $\sigma_{2}$ and $\sigma_{3}$ swapped orientations and dilational shear fractures and joints developed. A regional joint system developed only on the eastern margin of the basin. Although these joints have not been dated accurately, they are probably related to the Tertiary extension.

In the western and eastern margins, only dip-slip movements have been observed; no indication of reverse or strike-slip displacement has been found. This difference in structural style may be related to the Cretaceous inversion, which also reactivated preexisting faults.

No genetic fracture parameter data on the northern margin are available. Note, however, that the same fracture orientations are present as in the other areas, with more predominance of the E-W trending fractures (Table 2).

\section{Implication of fracture systems for reservoir be- haviour}

The results and interpretations presented above have been used to compare, at least qualitatively, the expected impact of fractures on reservoir behaviour with the observed reservoir behaviour.

A separate in-house reservoir-heterogeneity study over the eastern margin showed that well perform-

\begin{tabular}{|lcccc|}
\hline Triassic extension & Mid-Kimmerian extension & Late Kimmerian extension & Tertiary extension \\
\hline Early diagnesis & Main burial & Final burian & Uplift & Regional Jointing \\
\hline
\end{tabular}

A)

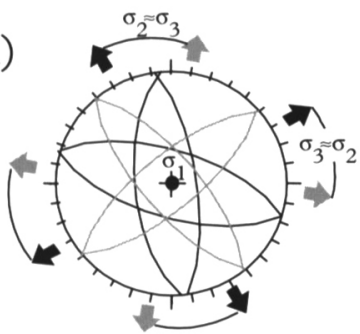

Particuliere flow shear fractures Dolomite cement

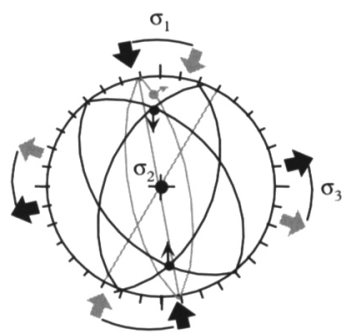

Cataclastic shears and dilational shears asscociated with joints Reverse offsets and strike-slip slikensides quartz / Fe-dolomite / siderite cements

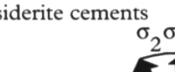

B)

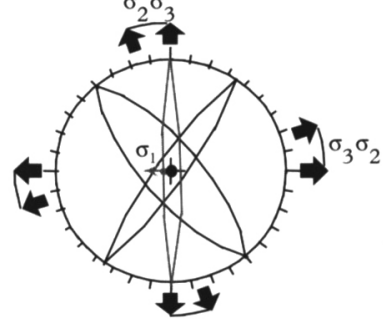

1) Cataclastic shear fracture Fe-Dolomite Cement

2) Dilational shear fractures and Joints Dip-slip slikensides

Quartz cement and Partially open

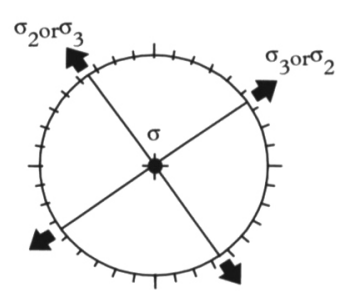

Joints and dilational shears Anhydrite cement and open

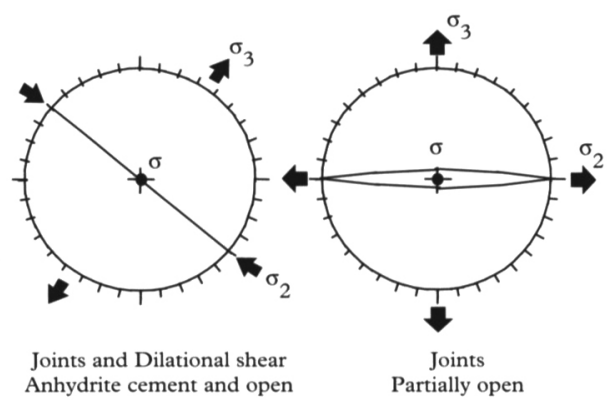
Anhydrite cement and open Partially open

Fig. 11. Paleostress orientation analysis and structural interpretation of the Rotliegend fracture system in the Broad Fourteens Basin (A) and its margins (B). Bars at top indicate local variations in space (in A) or in time (in B). 
ance is statistically related to hydrocarbon column height, to the density of NW-SE trending faults, and to the inverse of distance to NE-SW trending faults. These results can be interpreted in the light of the present fracture study, since faults and the occurrence of fractures are geometrically related. The NE-SW cataclastic shear fractures are cemented (Table 2), relatively long (Fig. 8) and tend to form anastomosing bands (Loosveld \& Franssen, 1992). Although the spacing of these bands is relatively large (Fig. 10), these bands tend to form continuous networks and may act as lateral barriers to fluid flow (Loosveld \& Franssen, 1992). Permeability reductions ( $K_{\text {fault rock }} /$ $\mathrm{K}_{\text {host rock }}$ ) observed in cataclastic shear fractures can be as high as 10-6 (Antonellini \& Aydin, 1994; Fulljames et al., 1996). NW-SE trending fractures are relatively short (Fig. 8), more densely distributed in space (Fig. 10), and they may be open (Table 2). They may therefore act as fluid conduits and enhance fluid flow.

The presence of relatively intensely fractured zones, particularly around NW-SE or N-S striking faults (Fig. 10) may also influence well performance, or induce heavy mud losses or early water production. The relations between the horizontal permeability $\left(\mathrm{K}_{\mathrm{h}}\right)$ predicted from reservoir modelling and that measured from well tests have been investigated (Fig. 12). Differences between these two permeabilities are often attributed to reservoir quality and/or well impairment but may be related to the presence of fractures as well. Indeed, one can note that wells showing a tested $K_{h}$ larger than the calculated $K_{h}$ are associated with E-W or NW-SE open fractures.

\section{Conclusions}

In the Broad Fourteens area, fracture systems can be interpreted in terms of the structural geological history of the area. Based on a statistical analysis and a geological interpretation of core and image-log data, three groups of fracture systems distributed along four orientation trends have been identified. These fracture systems formed in response to repeated reactivation of pre-existing fault trends under a fairly coaxial stress field with changes in stress magnitude resulting in swapping of the principal stress axes. The three groups are:

1 Fault-related fractures that consist of shears and dilational shears which occur close to, and parallel with, larger-scale faults. These fractures trend NESW and NW-SE; locally a N-S oriented system is developed. They formed during the Middle to Late Kimmerian rifting. The fracture systems were controlled by basement fault trends. The deformation

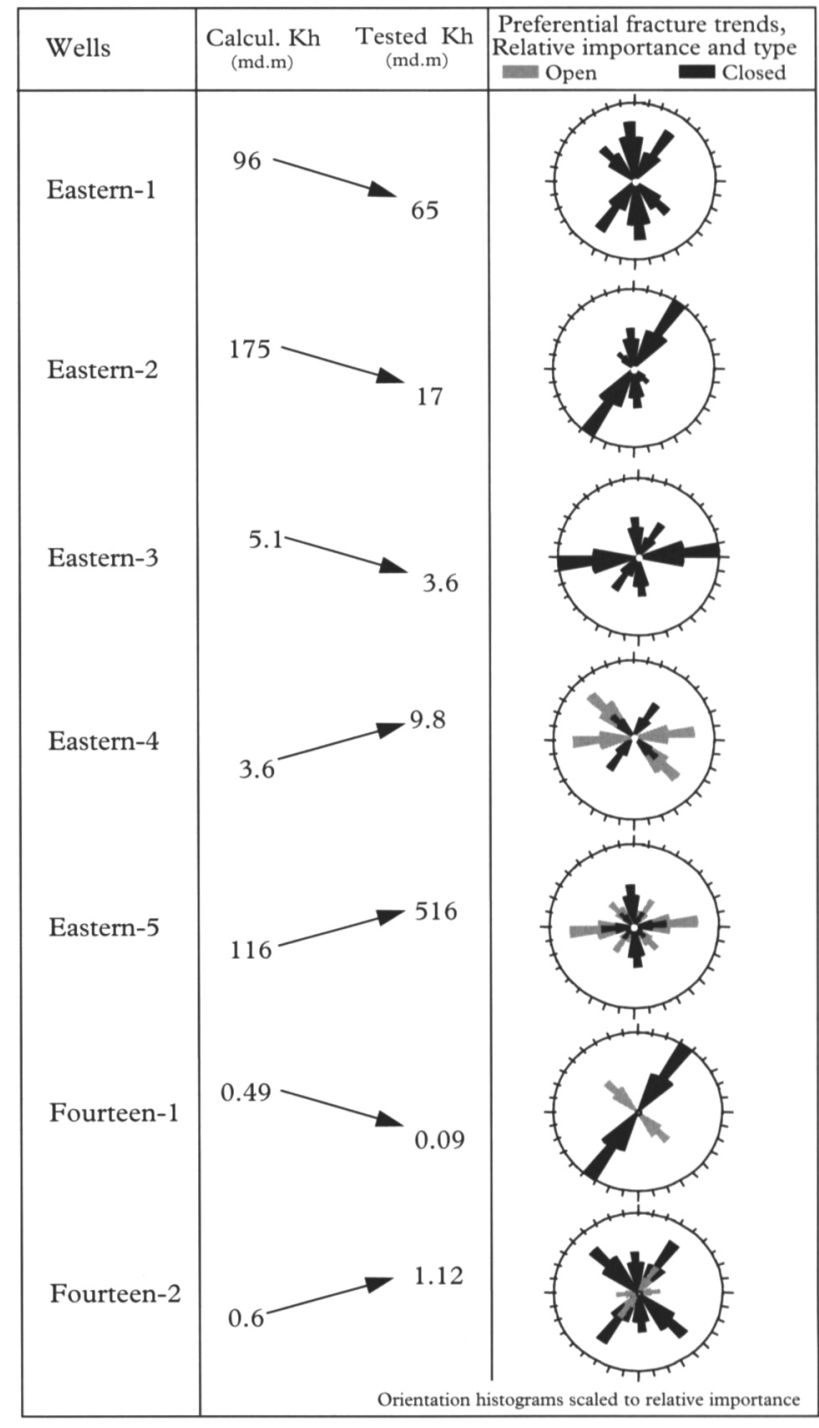

Fig. 12. Calculated versus tested permeability $(\mathrm{Kh})$ and relation with fracturing of the Rotliegend in the study area.

is characterised by multi-directional extension followed by oblique extension during the deepest burial.

2 Dilational shear and joints that propagate along the existing NW-SE and NE-SW trends are related to the Late Cretaceous uplift event, which resulted in a permutation of the principal stress axes.

3 Regional joint systems preferentially oriented around E-W to ESE-WNW. The timing of the development of these joints is difficult and may range from Late Jurassic to Late Tertiary. In the Broad Fourteens Basin, these regional joints are rare.

In good-quality sandstones, the fracture networks are not dense enough to control the reservoir behaviour. In fields with poor reservoir quality and small extent, however, they may have an impact. In such fields, fractures should be included in field development plans. The NE-SW trending fault-related shear fractures are generally relatively long and always cement- 
ed, so that they may compartmentalise reservoirs. N-S fault-related shear fractures are relatively short and cemented, and also tend to compartmentalise reservoirs. In contrast, the NW-SE trending fault-related shear and dilational shear fractures and the regional E-W joints are short and often partially open. Consequently, they may enhance reservoir flow properties. This type of impact of fractures on reservoir behaviour may assist the interpretation of well test results. Furthermore, the study results may be applied to future well designs. The presence of fracture networks should be considered in order to plan for fracture-induced losses during drilling, to optimise mud weight, etc. From a reservoir-development point of view, the well orientation should be optimised in order to maximise or minimise the number of intersected fractures. Furthermore, the well may be targeted in an area with high or low fracture densities.

\section{Acknowledgements}

We wish to thank the Nederlandse Aardolie Maatschappij BV , Energie Beheer Nederland BV, CLAM Petroleum Company, Clyde Petroleum Exploratie B.V. and Oranje-Nassau Energie BV for permission to publish these results. Comments by C.A. den Boer and H.W. Frikken and by an anonymous reviewer improved earlier versions of this manuscript. We thank G. Tiller (BTC, Houston, USA), R. Loosveld (P.D.O., Muscat, Oman) and S. Crouch (S.O.C., New Orleans, USA) who have contributed to the development of our ideas.

\section{References}

Antonellini, M.A. \& Aydin, A., 1994. Effect of faulting on fluid flow in porous sandstones: petrophysical properties. American Association of Petroleum Geologists Bulletin 78: 355-377.

Bartholomew, I.D., Peters, J.M. \& Powell, C.M., 1993. Regional structural evolution of the North Sea: oblique slip and the reactivation of basement lineaments. In: Parker, J.R. (ed.): Proceedings $4^{\text {th }}$ Conference on Petroleum Geology of Northwest Europe. Geological Society (London): 1109-1122.

Bergerat, F., Bouroz-Weil, C. \& Angelier, J., 1992. Paleostresses inferred from macrofractures, Colorado Plateau, Western USA. Tectonophysics 206: 219-243.

Diday, E,. 1971. Une nouvelle méthode en classification automatique de formes: la méthode des nuées dynamiques. Revue de Statistique Appliqué 21(2): 19-33.

Engelder, T., 1985. Loading path to joint propagation during a tectonic cycle: an example from the Appalachien Plateau, USA. Journal of Structural Geology 7: 459-476.

Engelder, T. \& Geiser, P., 1980. On the use of regional joint sets as trajectories of paleostress field during the development of the Appalachian Plateau, New York. Journal of Geophysical Research 85: 6319-6341.

Franssen, R.C.M.W., Brint, J.F., Sleeswijk Visser, TJ. \& Beecham, A., 1993. Fracture characterization and diagenesis in the Clipper
Field, Sole Pit Basin, southern North Sea. In: 1993 American Association of Petroleum Geologists International Conference and Exhibition (The Hague) Abstracts: 48.

Frikken, H.W., 1996. CBIL logs: vital for evaluating disappointing well and reservoir performance, K15-FG field, central offshore Netherlands. In: Rondeel, H.E., Batjes, D.A.J. \& Nieuwenhuijs, W.H. (eds.): Geology of gas and oil under the Netherlands. Kluwer (Dordrecht): 103-114.

Fulljames, J.R., Zijerveld, L.J.J., Franssen, R.C.M.W., Ingram, G.M. \& Richard, P.D., 1996. Fault seal processes: systematic analysis of fault seals over geological and production time scales. In: Hydrocarbon seals, importance for exploration and production - Proceedings of the Norwegian Petroleum Society Hydrocarbon Seals Conference (Trondheim), Petroleum Abstract: 641329.

Glennie, K.W., 1990. Lower - Permian Rotliegend. In: Glennie, K.W. (ed.): Introduction to the petroleum geology of the North Sea. Blackwell Scientific Publication: 120-152.

Hancock, P.L., 1985. Brittle microtectonics: principles and practice. Journal of Structural Geology 7: 437-457.

Homann, H. \& Gauthier, B.D.M., 1995. Sampling fracture parameters in Borehole Imaging Logs and cores: an integrated approach applied to the Dutch Offshore. American Association of Petroleum Geologists Bulletin 79: 1222; Petroleum Abstract: 610695.

Huang, Q. \& Angelier, J., 1989. Fracture spacing and its relation to bed thickness. Geological Magazine 104: 550-556.

Kulander, B.R., Dean, S.L. \& Ward Jr., W.J., 1990. Fractured core analysis - interpretation, logging and use of natural and induced fractures in core. In: American Association of Petroleum Geologists Methods in Exploration 8: $88 \mathrm{pp}$.

Kulatilake, P.H.S., 1988. State-of-the-art in stochastic joint geometry modelling key questions. In: Cundall (ed.): Rock mechanics. Balkema (Rotterdam).

Kulatilake, P.H.S., Wu, T.H. \& Wathugala, D.N., 1990. Probabilistic modelling of joint orientation. International Journal on $\mathrm{Nu}-$ merical Analytical Methods in Geomechanics 14: 325-350.

Ladeira, F.L. \& Price, N.J., 1981. Relationship between fracture spacing and bed thickness. Journal of Structural Geology 3: 179-183.

Loosveld, R.J.H. \& Franssen, R.C.M.W., 1992. Extensional vs. shear fractures: implications for reservoir characterisation. European Petroleum Conference (Cannes, 16-18 November) Proceedings 2, Paper SPE 25017: 65-66.

Mardia, K.V,. 1972. Statistics of directional data. Academic Press (London): $357 \mathrm{pp}$.

Mulder, G., Busch, V.:.P., Reid, I., Sleeswijk Visser, T.J. \& Van Heyst, B.G., 1992. Sole Pit: improving performance and increasing reserves by horizontal drilling. European Petroleum Conference (Cannes, 16-18 November) Proceedings 2, Paper SPE 25025: 83-94.

Narr, W. \& Lerche, I., 1984. A method of estimating of subsurface fracture density in core. American Association of Petroleum Geologists Bulletin 68: 637-648.

Narr, W. \& Suppe, J., 1991. Joint spacing in sedimentary rocks. Journal of Structural Geology 13: 1037-1048.

Price, N.J. \& Cosgrove, J.W., 1990. Analysis of geological structures. Cambridge University Press (Cambridge): $502 \mathrm{pp}$.

Priest, S.D. \& Hudson, J.A., 1976. Discontinuity spacing in rocks. International Journal of Rock Mechanics, Mineral Science \& Geomechics, Abstracts 13: 135-148.

Reches, Z., 1983. Faulting of rocks in three-dimensional strain field. II Theoretical analysis. Tectonophysics 95: 133-156.

Rives, T., Razack, M., Petit, J.P. \& Rawnsley, K., 1992. Joint spacing periodicity: field data, analogue and numerical modelling. Journal of Structural Geology 14: 925-937.

Terzaghi, R.D., 1964, Source of error in joint surveys. Geotechnique 15: 287-304. 
Van Adrichem Boogaert, H.A. \& Kouwe, W.F.P., 1993. Stratigraphic nomenclature of the Netherlands, revision and update by RGD and NOGEPA. Mededelingen Rijks Geologische Dienst (Haarlem) 50 .

Van Wijhe, D.H., 1987. Structural evolution of inverted basins in the Dutch offshore. Tectonophysics 137: 171-219.

Watson, G.S., 1966. The statistics of orientation data. Journal of Geology 74: 786-797.
Wride, V.C., 1995. Structural features and structural styles from the five Countries area of the North Sea Central Graben. First Break 13: 395-407.

Wu, H. \& Pollard, D.D., 1995. An experimental study of the relationship between joint spacing and layer thickness. Journal of Structural Geology 17: 887-905.

Ziegler, P.A., 1982. Geological atlas of Western and Central Europe. Elsevier (Amsterdam): $130 \mathrm{pp}$. 